Bol. Acad. peru. leng. 61. 2016 (199-232)

\title{
Tahuashando. Enigma culle en la poesía de Vallejo
}

\author{
Tahuashando. \\ Culle enigma in Vallejo's poetry \\ Í́BICO Rojas \\ Universidad Nacional Mayor de San Marcos
}

Resumen:

Este trabajo está referido al estudio de las voces culles en la poesía de César Vallejo. En forma especial, revisamos las explicaciones que se han dado, desde una perspectiva quechuista, acerca del origen y significado del neologismo «tahuashando». Y ensayamos una nueva explicación a partir del sustrato culle en el castellano andino de la sierra de La Libertad.

Abstract:

This investigation refers to the study of Culle words in Cesar Vallejo's poetry. We, specially, analyze from the Quechua point of view, the origin and meaning of the "tahuashando» neologism. And, we consider a new explanation from the Culle language in the Andean Spanish of La Libertad highland. 
Palabras clave: Huasha, tahuasha, tahuashando, reverenciando.

Keywords: Huasha, tahuasha, tahuashando, in owe of.

Recibido: 15/10/2016

Aceptado: 31/10/2016

A Ricardo González Vigil

\section{Los huamachucos y su lengua}

Los «guamashugos» (acaso, llamados así originariamente) hablaban culle. Soñaban y amaban en culle, gozosos. Cuando llovía con rayos, relámpagos y truenos, presagiaban cautelosos y oraban en culle, con un coro infinito de insectos y aves. Cantaban y bailaban surcando la tierra, con embriaguez. Pastaban el ganado, cosechaban bajo el sol y se sentían bienaventurados. Hilaban y tejían su fantasía en la urdimbre de los hilos, y eran felices. Cuando respiraban el aire fresco de la libertad, también lo eran.

Lo fueron las enormes poblaciones de los extensos curacazgos de Cajamarca, Huamachuco y Conchucos, quesaturaban su universo con teónimos, topónimos, orónimos, hidrónimos, zoónimos y fitónimos culles, voces de una lengua, hoy, exótica; sin fecha de origen ni procedencia lingüística, sin filiación en ningún catálogo de lenguas ni registro de desactivación, pero con vestigios irrecusables de un pueblo laborioso encumbrado en los Andes, en aldeas y grandes ciudades, planeadas con buen criterio urbanístico, provistas de importantes obras hidráulicas, en las que se desarrollaba 
una cultura teocrática con dioses muy poderosos como Ataguju, adorado especialmente en el templo que se le comenzó a construir en el siglo V, en Marcahuamachuco -monumental por sus dimensiones y diseño arquitectónico-; y Catequil, al que se rendía culto desde Cuzco hasta Quito, según los relatos de los primeros agustinos «doctrineros», llegados a Huamachuco a mediados del siglo XVI (Agustinos 1992 [c1561]).

Los culles vivieron en libertad y con sencillez, hablando su lengua general ${ }^{1}$, por lo menos, desde el siglo III a.C. hasta la segunda mitad del siglo XIV, cuando asomaron por sus tierras los incas, con ingentes huestes y la inveterada historia de la civilización superior, para sojuzgarlos, cobrarles tributos y obligarlos a convivir con grandes poblaciones mitimaes que tenían costumbres diferentes y hablaban otras lenguas: quechua, chimú, cañari, una lengua jíbara y una arawak (Rojas 2011). La situación se agravó cuando los españoles los despojaron de todo, los explotaron en los campos agrícolas, en los obrajes y en las minas, los bautizaron y les impusieron la lengua de Castilla.

Los pobladores nativos debieron adaptarse al multilingüismo impuesto, lo que no habría sido fácil, porque el contacto desequilibrado, entre los grupos humanos involucrados, favorecía unas lenguas en desmedro de otras. En un primer momento, el autoritarismo imperial cuzqueño fortaleció el uso del quechua. Después, la imposición hispánica hizo lo propio

Teniendo como referencia el antiquísimo y abundante multilingüismo de los Andes centrales, es razonable imaginar la coexistencia, en el área culle, de algunas lenguas practicadas por algunas comunidades endogámicas pequeñas, ubicadas en lugares montañosos poco accesibles. 
con el castellano, mientras las lenguas menores eran replegadas y desactivadas aprisa.

La población culle, la más extendida en la sierra norteña del antiguo Perú, debió tolerar, por efecto de las sucesivas conquistas: incaica y castellana, los mecanismos más drásticos de desplazamiento social de su lengua, en las prácticas comunicativas, durante el incanato y los trescientos años coloniales; a los que seguiría la acelerada desactivación de esta en el transcurso de los primeros cien años de la República. Al término de los cuales, habrían muerto los poquísimos cullófonos aún sobrevivientes por esos años; $\mathrm{y}$, consecuentemente, en sus cerebros se habrían desintegrado los últimos sistemas gramaticales, en particular, las estructuras semánticas léxicas y composicionales, componentes fundamentales de la competencia lingüística de esa lengua.

Pero, en realidad, no se había perdido todo. Por entonces, en el habla de los nuevos pobladores castellanófonos de aquella región todavía se mantenían en uso, además de teónimos, topónimos, orónimos, hidrónimos, zoónimos, fitónimos y algunos antropónimos, abundantes lexemas (o morfemas con significado léxico) y gramemas (o morfemas con significado gramatical) correspondientes al universo huamachuco, que constituyen uno de los sustratos mayores del castellano hablado en esa parte del Perú.

En Santiago de Chuco, en el área central de los antiguos huamachucos, el infante, el púber, el adolescente, el joven César Vallejo, nacido allí, en 1892, no habría sido inmune al flujo culle perviviente en el 
habla castellana de su pueblo y menos al fonema $/ \mathrm{S} / 2$, elemento tan identificativo de dicha lengua andina. Más tarde, convertido en estudiante de leyes, con más sensibilidad poética que vocación de abogado ${ }^{3}$, enriqueció su idiolecto con el dialecto costeño de Trujillo, en especial, con el habla académica de la universidad. En tanto, sus concepciones intelectuales evolucionaban de forma irrefrenable en los diálogos sensibles, inspiradores, inteligentes y esclarecedores, sostenidos con sus amigos del Grupo de Trujillo, a la postre, Grupo Norte ${ }^{4}$, con los que compartía el ideal de impulsar, modernizar y transformar la vida cultural de la sociedad trujillana y de toda América Latina. La meta final era liberarla del virreinato intelectual europeo. Y si bien el plan no se concretaría en forma integral y simultánea, su poesía inició la emancipación literaria de esta parte del Nuevo Mundo y trascendió los ideales juveniles, embellecida con inevitables voces culles.

2 Al respecto, Ciro Alegría dice: «En la clase, hablaba Vallejo lentamente, pronunciando las eses al modo de su Santiago de Chuco: «Niñosh... La Tierra esh redonda como una naranja. Eshta mishma Tierra en que vivimosh y vemosh como si fuera plana, esh redonda». Cita tomada de Monguió (1952: 33).

3 Si bien en algún momento se vinculó con ciertos asuntos legales, al lado de su padre y de su hermano Néstor, cuando este se desempeñaba como juez en Huamachuco, al parecer, prefirió la docencia. Trabajó como profesor en el «Centro Viejo» (Centro Escolar de Varones $N^{\circ}$ 241) y en el Colegio Nacional de San Juan, de Trujillo, asimismo, en el Colegio Nacional de Nuestra Señora de Guadalupe, en Lima.

4 Los miembros del «Grupo Norte», entre cuyas figuras destacan César Vallejo, Víctor Raúl Haya de la Torre, Antenor Orrego, José Eulogio Garrido, Alcides Spelucín y Carlos Valderrama, en los años iniciales se llamó «Grupo de Trujillo», después, con la aparición del diario El Norte, en 1923, adoptaron el nombre con el que pasaron a la historia. Contrariamente a lo que se difunde, nunca aceptaron ni usaron la etiqueta de «Bohemia de Trujillo» con la que Juan Parra del Riego los presentó en la revista Balnearios, publicada en Lima (22 de octubre de 1916). 
En lo que va del siglo XXI, pareciera que la situación sociolingüística de la sierra de La Libertad va adquiriendo un impulso sumamente alentador en relación con los rezagos culturales. Tenemos la impresión de que los jóvenes pobladores, a partir del rescate del culle como lengua ancestral de la región, iniciado en la segunda mitad del siglo pasado, están operando una revivificación del sentimiento de identidad con su cultura patrimonial, en particular, con la lengua que la expresa, es decir, con lo que queda de aquella, con los sonidos, los vocablos, los afijos; todavía presentes en los diálogos cotidianos, a la hora de los alimentos, en la cocina, en los talleres artesanales, en el campo y en la ciudad. Por ejemplo, hoy, Samuel Blas, de Santiago de Chuco, y Emilio León, de Cajamarca, dos jóvenes estudiantes de la Universidad Nacional de Trujillo, realizan trabajos de investigación, para sus tesis de maestría en lingüística, sobre los procesos de nominalización de los verbos culles en el castellano de la sierra liberteña y la persistencia de los apreciativos culles en la misma área dialectal. Y, por cierto, cada día son más los estudiosos interesados en el registro de nuevas muestras del léxico culle, con miras a incrementar el corpus de esa lengua y develar, en forma progresiva, sus procesos de significación. Todo lo cual redundará en la incentivación de investigaciones futuras más ambiciosas y, sin duda, en el reforzamiento de la identidad cultural de los huamachucos contemporáneos, por encima de los lindes provinciales.

\section{El culle en la poesía de Vallejo}

En un trabajo realizado hace cuatro años (Rojas 2012), pudimos reconocer las cuatro únicas voces culles que 
usó César Vallejo en su poesía: Tayanga $a^{5}$ Irichugo ${ }^{6}$, poñ $a^{7}$ y tahuashando ${ }^{8}$, de las cuales, mediante recursos morfológicos, solo pudimos confirmar plenamente la filiación culle de las tres primeras.

Tanto Tayanga como Irichugo son topónimos. El primero es el nombre de un caserío del distrito de Marcabal (prov. de Sánchez Carrión). En este se puede observar, al final de la palabra, la secuencia fónica -nga que, por su alto índice de aparición en el área culle, se convierte en el primer indicio de filiación con esta lengua; pero también es frecuente una secuencia mayor: -ayanga (Tayanga) o ayanga- (Ayangay). Estos elementos y su uso reiterado en el área nuclear de dicha lengua, nos hicieron pensar que Tayanga sería un topónimo culle9.

5 En la estrofa final del poema «Terceto autóctono», verso 40.

6 En la tercera estrofa del poema «Mayo», verso 21.

7 En la estrofa final del poema «Guitarra», verso 25.

8 En la estrofa final del poema «Hojas de ébano», verso 41.

9 Según Félix Quesada (en una comunicación personal), «Tayanga» deriva del quechua «taya» (nombre de un árbol). Rodolfo Cerrón, en una nota personal, descarta esta suposición, porque «taya» «no se aviene con un sufijo derivador» con función locativa como -nqa (o -nga en el quechua chinchaisuyo). Hipotetiza más bien que «Tayanga» sería un híbrido aimara-quechua, en el que la raíz ambivalente aimara «thaya» es «frío» o "hacer frío» y la desinencia quechua -nqa (moderna -na) es un derivador con función locativa. La expresión se traduce así: «Lugar donde hace frío». Esto nos obliga a esperar la confirmación de la conjetura de Rodolfo, a fin de poder revisar la nuestra. No obstante, debemos anotar que Tayanga es un caserío del distrito de Marcabal (prov. de Sánchez Carrión), ubicado en una zona cálida, y que al lado este del área culle, a la margen derecha del Marañón, encontramos el topónimo Tayabamba (variante de Tayapampa, topónimo de un anexo del distrito de Cochorco, prov. de Sánchez Carrión), con el que se designa a la capital de Pataz (región La Libertad), porque habría sido fundada en un área plana de clima templado, en la que -según algunos pobladores bien informados- abundaban campos de tayanca, arbusto silvestre, espinoso, de unos cinco metros de altura, utilizado como leña. Todavía existen algunas áreas de tayanca cercanas a esa ciudad. Esta planta es diferente al árbol de taya o tara, que llega a unos doce metros de altura y produce unas semillas envainadas de gran valor industrial (esta nota fue leída por Rodolfo y es publicada con su autorización). 
Con iguales criterios, afirmamos que Irichugo, conformado por el lexema culle //-chugo// ( $</ /$ shugo//), que significa 'tierra', también es un topónimo de la misma lengua, con el que se denomina a un lugar cercano a una colina, ubicada a poca distancia de Santiago de Chuco, según me había contado Cristóbal Campana, estudioso notable, nacido en esa ciudad. Juan Larrea (1978: 802), coincidentemente, registra lo siguiente: «Irichugo. (Mayo, 21) ${ }^{10}$. Lugar al pie del cerro San Cristóbal, a tres kilómetros de Santiago, donde los Vallejo poseían una propiedad». Al respecto, hace pocos meses, tuve la oportunidad de entrevistar a algunos profesores de educación básica que trabajan en Santiago. Curiosamente, reconocían el carácter culle del nombre Irichugo, pero no tenían noticias de ese lugar, lo que me hizo pensar que, tal vez, por ser muy pequeño no trascendía su nombre, o porque el topónimo estaba cayendo en desuso.

Por último, la voz poña es un sustantivo común, usual hasta hoy en la que fuera el área culle, con el que se hace referencia a una pajilla, brizna o pelusa vegetal que, al contactar con la membrana conjuntiva del ojo humano, produce una picazón o escozor muy molesto. Por eso, cuando una persona es afectada por una poña, de inmediato, pide a otra que le sople el ojo con fuerza, hasta liberarlo de esa pelusa insoportable.

Ciertamente, este significado nos permite entender con suma claridad el irritante y extraño sufrimiento, expresado por Vallejo en los versos 25 y 26 de su poema «Guitarra»:

10 Esto hace referencia al verso 21 del poema «Mayo». 
de esperar con pujanza y mala poña;

el placer de sufrir...

Hasta aquí nuestras convicciones ${ }^{11}$ acerca de las voces culles universalizadas por el autor de Los heraldos negros. Lo referente a «tahuashando» es una larga historia de tributos sentimentales, desvelos imaginativos y de adivinaciones, que ojalá no sea de nunca acabar.

\section{Una palabra clave}

En el castellano andino hay palabras que, por ser percibidas como impropias del castellano, son consideradas por lo general como provenientes de la lengua quechua, acaso por la secular y fuerte presencia de esta lengua en las poblaciones de la sierra. Y, por supuesto, no faltan los aficionados a la etimología que, a partir de tal presunción, les atribuyen étimos quechuas con criterio analógico, pero sin precisión semántica, y sin tomar en cuenta los elementos de otra lengua del antiquísimo multilingüismo preincaico y prehispánico. Siguiendo dichas prácticas, en la antigua área culle, por ejemplo, encontramos varios casos entre los que, tal vez el más difundido, sea el referente al topónimo Huamachuco $^{12}$.

11 Para una información más amplia sobre el estudio de las voces culles en la poesía de Vallejo se puede ver Rojas (2012).

12 En esta región, muchas personas creen todavía que el topónimo «Huamachuco» se origina en las voces quechuas huaman (que denota al ave 'halcón') y chucu (con el que se hace referencia a 'sombrero'), por consiguiente, «Huamachuco» haría alusión a 'sombrero de halcón'. Etimología sumamente cuestionable, tal como lo señalamos en un trabajo anterior (Rojas 2012). En primer lugar, porque el sombrero no existía en los pueblos originarios andinos. Lo trajeron los españoles; en segundo lugar, porque la palabra chucu en el quechua prehispánico no significaba 'sombrero'; y, en tercer lugar, porque en la sierra de la actual región La Libertad la población originaria se identificaba, desde antes de la invasión incaica, con 
Por razones similares, todas las palabras de origen extraño al castellano, encontradas en la poesía de César Vallejo, son consideradas -casi sin titubeos- como quechuismos por muchos estudiosos vallejistas ${ }^{13}$, aunque las descripciones morfológicas y las interpretaciones semánticas no siempre sean satisfactorias. Sin embargo, una observación atenta nos permitió identificar algunas palabras de origen culle y no quechua, como se creía generalmente. Una de esas palabras, por ser un neologismo muy extraño suscitó, desde hace décadas, inevitables especulaciones que, si bien no resolvieron las interrogantes sobre su origen y significado, sirvieron para acentuar la inquietud intelectual y la continuidad en las indagaciones.

Desde luego, en el ámbito de las ciencias humanas, sobre todo, cuando los objetos de estudio son realidades abstractas: cultura ${ }^{14}$, pensamiento, memoria, sentimientos, volición, significados, lengua, estética, etc., los

el etnónimo «Guamashugo» (o «Guamanchoro», según el deficiente registro de Miguel de Estete (1968 [1535]: 243). Adelaar (1989) plantea una etimología más adecuada. El etnónimo Guamashugo, por un proceso de quechuización se habría convertido en «Guamachucu» y, luego, por un proceso de castellanización habría adquirido la forma «Guamachuco» que, de acuerdo con las normas ortográficas dispuestas por la Iglesia católica, a fines del siglo XVI, para la transcripción de los vocablos quechuas, debió ser escrita tal como la conocemos ahora: Huamachuco. Antes de la conquista incaica, con este término se hacía referencia básicamente a toda la región de la actual sierra liberteña, después, la referencia se restringió a la provincia y más tarde a la ciudad.

13 Entre los tantos, Ángeles Caballero (1955), Juan Larrea (1978), M. Marticorena (1993) y J. Guzmán (2000).

14 En pocas palabras, podemos decir que la cultura es la capacidad mental de «cultivar», de refinar los conocimientos, los pensamientos, los sentimientos, las habilidades humanas, asimismo, de producir nuevos contenidos y formas expresivas. Los patrones sociales, los artefactos artesanales, artísticos y tecnológicos son "productos culturales» en cuanto son generados por la «cultura», pero no constituyen la cultura en sí, como se considera, generalmente, desde un punto de vista objetivo, antropológico. 
hallazgos felices no son sencillos ni frecuentes; puesto que, los fundamentos y mecanismos mentales de tales hechos, siguen siendo secretos muy bien guardados en el cerebro humano, de los cuales solo tenemos algunas referencias a partir de sus expresiones objetivas y de algunas hipótesis racionalmente consistentes. Condiciones que hacen más arduo y tal vez menos seguro el trabajo investigativo en este ámbito, y quizá por lo mismo, este nos parezca tan desafiante y seductor.

Atraídos por lo último, hoy volvemos a aventurarnos -en el cabal sentido de la palabra- en la dilucidación de un hecho lingüístico que desvela, desde hace décadas, a un buen número de estudiosos de la poesía de César Vallejo, a quien se le celebra no solo el virtuosismo de explorar al máximo la función poética del lenguaje, sino también la capacidad de creación de nuevas formas léxicas, tributarias de la armonía y cadencia de sus versos, casi todas, de raigambre castellana. Una de las excepcionales, por ejemplo, a pesar de sus apariencias formales, no es castiza de una de las lenguas en contacto en el área nuclear culle. Es una palabra característica del proceso formativo del castellano andino, particularmente, del que se extiende por el sur de Cajamarca, la sierra liberteña y el norte de la sierra ancashina.

Después de una indagación larga y persistente, nuestra aventura se orienta ahora a esbozar una posible estructuración morfológica y una semantización lírica de aquel vocablo singular creado por el gran César Vallejo, la voz poética más alta del Grupo Norte, el grupo de más alta calidad humana e intelectual que haya surgido en el Perú hasta estos días. Ese vocablo 
es \#tahuashando\# ${ }^{15}$, escrito por única vez en el poema «Hojas de ébano» de Los heraldos negros. Palabra clave para entender los procesos de interferencia producidos en el contacto de lenguas en la sierra norteña, así como para resaltar la íntima relación entre la lingüística y la poética, ligazón tan apreciada por Roman Jakobson (1975) y George Steiner (1971, 2011 [1999]) $\mathrm{y}$, desafortunadamente, desestimada o poco atendida por los críticos literarios. Pero es clave, como ninguna otra, para percibir la forma en que Vallejo se entraña con su Santiago de Chuco ancestral, natal, aldeano, universal.

\section{El enigmático gerundio tahuashando}

El profesor César Ángeles Caballero (1955) tiene el mérito de haber sido, si no el primero, uno de los primeros en tratar de evidenciar algunos peruanismos en la poesía de César Vallejo. En ese afán, dedicó especial atención a la extraña palabra \#tahuashando\#, cuyo étimo es, con absoluta seguridad -según él-, un vocablo procedente de la lengua quechua.

De acuerdo con lo señalado en las primeras líneas del punto 3 de este trabajo, la analogía que se observa a primera vista entre la parte inicial de \#tahuashando\# y la palabra quechua \#tawa\#, que significa 'cuatro' -escrita como \#tahua\#, según las normas ortográficas dispuestas por la jerarquía católica del virreinato peruano, a fines del siglo XVI (Rojas 2012)-, le sirve de base a Ángeles para aseverar que el vocablo vallejiano deriva

15 A partir de aquí usamos el carácter \# para marcar los límites de una palabra, sea oral o escritural. 
del numeral quechua \#tahua\# y que el poeta le habría dado forma de gerundio para significar 'de cuatro en cuatro'. Más tarde, Juan Larrea (1978: 808) y Manuel Marticorena (1993), quechuófono nacido en Huancavelica, afirmaron lo mismo. Ángeles agrega que Vallejo habría usado ese recurso para intensificar la subjetividad y fuerza expresiva de dicho vocablo, por eso él la percibe «con un fondo afectivo y con algo de rumor impresionista». Apreciación que trata de justificar con el siguiente argumento:

Si pretendiéramos sustituir el vocablo «tahuashando» por su traducción literal «de cuatro en cuatro», el verso perdería trascendencia, su esencia afectiva, su contenido; trascendencia, afectividad y contenido, que apreciamos hondamente los que conocemos el verdadero fondo estilístico del idioma quechua. (Ángeles 1955: 6)

Afirmaciones acerca de las cuales debemos observar, en principio, la imposible sustitución de \#tahuashando\# por el sintagma de régimen prepositivo «de cuatro en cuatro», porque esta no solo afectaría el contenido afectivo y el fondo estilístico del idioma quechua, sino, esencialmente la estructura semántica del verso castellano, hecho revelador de la impracticabilidad de la supuesta conmutación, debida, desde luego, a que la expresión «de cuatro en cuatro» no es equivalente a \# tahuashando\#. Pero si, en el supuesto negado, tal sustitución fuera posible, los versos serían estos:

... los viejos alcanfores

que velan [de cuatro en cuatro] en el sendero con sus ponchos de hielo y sin sombrero. 
Lo que significaría que los viejos alcanfores hacen guardia en el sendero y se relevan periódicamente de cuatro en cuatro, o que están agrupados de cuatro en cuatro a lo largo del sendero. Significados que, en nuestra lengua, no podrían estar asociados a ninguna forma de gerundio. Pues, en este caso, el gramema/// -ndo // ${ }^{16}$, correspondiente al gerundio castellano, carece de significado léxicoo conceptual, por lo cual es improbable la añadidura o transferencia al lexema // tawa // (o a su forma escrita // tahua // ) de semas cuantificadores, de agrupamiento, de periodización y menos de duplicación o reduplicación de agrupamientos, como los que supone el sintagma: «de cuatro en cuatro». Por eso, ningún hispanófono usa un gerundio con significados de esta clase, y menos lo habría hecho César Vallejo. Su buen conocimiento idiomático hace impensable que hubiese creado dicho vocablo para expresar el significado que se le atribuye.

Observamos, asimismo, que Ángeles Caballero, en su descripción gramatical, obvia un elemento de apariencia simple, pero de gran importancia para la investigación. Solo se refiere al lexema//tahua-// y a la terminación // -ando // como forma de gerundio, pero deja sin explicación el dígrafo «sh» que representa el fonema $/ \mathrm{s} /$ cuyos rasgos articulatorios son: [+ posalveolar], [+fricativo], [-sonoro] (o sordo). Unidad fonológica inexistente en la lengua quechua y en la castellana, pero de alta frecuencia de uso en la lengua culle; y que, dentro de la estructura de \#tahuashando\#, si no forma parte del lexema ni del gramema, debería cumplir necesariamente alguna función gramatical. En un

16 A partir de aquí usamos la doble barra// para indicar la delimitación de morfemas. 
sistema lingüístico no existe un elemento que no sea funcional.

En su libro Tahuashando. Lectura mestiza de César Vallejo, el estudioso chileno Jorge Guzmán (2000) se basa en el mismo supuesto de Ángeles. Esto es, que la invención lexical del poeta deriva del vocablo quechua \#tawa\#, que significa lo mismo que el numeral castellano \#cuatro\#, al que Vallejo agregó «el infijo -sh-, que confiere al verbo una larga imperfectividad, más la terminación española de gerundio» lo que -según Guzmán (2000: 68)- dio como resultado un neologismo castellano sobre la base de una palabra quechua por efecto de un proceso de «mestización lingüística». Asimismo, de acuerdo con su método de análisis literario, la palabra \#tawa\# en la poesía de Vallejo sería un hipograma, por lo que su significado podría estar estructurado con el concurso de semas correspondientes a diferentes realidades. Sin embargo, para Guzmán, \#tahuashando\# significaría lo mismo que \#cuatreando\# en castellano, gerundio del verbo \#cuatrear\# «en el sentido de ser cuatro». Según este criterio, los versos 40, 41 y 42 del poema «Hojas de ébano» podrían ser leídos así:

... los viejos alcanfores
que velan [cuatreando] en el sendero
con sus ponchos de hielo y sin sombrero.

El análisis propuesto del término \#tahuashando\#, a nuestro juicio, requiere algunas anotaciones gramaticales relacionadas con la forma -sh-, considerada por Guzmán como un infijo de imperfectividad. En 
principio, conviene resaltar la inexistencia en quechua y en castellano del fonema $/ \int / \mathrm{y}$, por consiguiente, del supuesto infijo //-sh-//. Por otro lado, si bien en la lengua culle existe el fonema $/ \mathrm{J} /$, nadie ha evidenciado, hasta ahora, su funcionamiento como infijo en la morfología de dicha lengua. Y respecto a este tipo de morfemas, en nuestra lengua el segmento «it» solo funciona como infijo cuando, al ser insertado en un lexema, lo convierte en discontinuo, es decir, fracciona su unidad morfológica pero no semántica, como ocurre, por ejemplo, en \#Nestitor\#, \#garuíta\#, \#caletita\#, \#latita\#, \#botita\#, casos en los cuales los lexemas son fragmentados en dos partes: //Nest_or //, //garú_a//, // calet_a //, // lat_a //, //bot_a//, sin afectar su significado básico. A la vez, este infijo agrega al lexema un tratamiento apreciativo, pero no una categoría aspectual. Desde este punto de vista, en \#tahuashando\# -como en cualquier otro gerundio castellano-, la imperfectividad ${ }^{17}$ está marcada por el gramema //-ndo // y no por el fonema $/ \mathrm{s} /$. De todo esto se puede colegir que //-sh-// no es un infijo ni un intensificador de imperfectividad. De tal manera que, la presencia del supuesto infijo //-sh- //, hasta aquí, continúa sin una explicación adecuada.

En cuanto al aspecto semántico, es pertinente considerar que el verbo \#cuatrear\# deriva del nombre \#cuatrero\#, con el cual, según el diccionario académico de la lengua castellana, se expresa el significado: «Que hurta o roba cuadrúpedos». En otras palabras: que roba ganado, particularmente, caballos. Esto

17 El sentido de continuidad del proceso significado por el verbo. 
último es relevante porque el sustantivo \#cuatrero\# en germanía derivó del numeral \#cuatro\# con el significado de 'caballo'. Pues, mediante una sinécdoque, los delincuentes llamaban \#cuatro\# al caballo ${ }^{18}$ en referencia a sus cuatro patas. De acuerdo con esta etimología, \# cuatreando\# solo puede significar 'robando caballos', por lo que, dicho gerundio, alteraría por completo la estructuración semántica de los versos que examinamos.

Quizá por esa razón, Guzmán tiene el cuidado de señalar que toma como forma básica el verbo \#cuatrear\# «en el sentido de ser cuatro». Pero no revela nada acerca de cómo entender un infinitivo con significado de sustantivo numeral; y menos, cómo entender el gerundio \#cuatreando\# en el sentido 'de ser cuatro', acaso para significar 'siendo cuatro'. Esto, indudablemente, plantea un problema crucial: cómo descubrir la estructura de un neologismo literario mediante el recurso de un galimatías.

Sin explicaciones adecuadas y siguiendo la idea «de ser cuatro», planteada por Jorge Guzmán, solo atinamos a imaginar como una posible significación del gerundio \# cuatreando\#, que los viejos alcanfores (humanizados) velan pronunciando el número cuatro o trazándolo en el aire, en forma prolongada o reiterada, o velan desplazándose como cuadrigas para reafirmar que son cuatro, o simplemente, como dice el profesor Ángeles, que los viejos alcanfores velan de cuatro en cuatro. Pero iqué relevancia poética podría

18 Ver María Moliner (1970), Diccionario de uso del español. También, Clave. Diccionario de uso del español actual (2000). 
tener la cuantificación de los alcanfores? En cualquier caso, la inadecuación semántica, como ya lo hemos señalado, es evidente. No solo porque los significados propuestos son discordantes con la forma del gerundio castellano, sino esencialmente porque son disonantes con el entorno intelectual, esto es, con la atmósfera de abstracción, de recogimiento y dolor creada por el autor en relación con el ámbito sepulcral de su madre; incluso, son extraños a la poética vallejiana que no es anagramática. Dicho esto, podemos reafirmar que, si Vallejo hubiese deseado acentuar la cantidad de los viejos alcanfores y humanizarlos de alguna forma, sin duda alguna, habría encontrado o creado una palabra exenta de enigmas semánticos tan complejos.

Por su parte, Rodolfo Cerrón-Palomino plantea una explicación distinta. Después de leer el original de este trabajo, en una conversación de café, me dijo que \#tahuashando\#, efectivamente, proviene del quechua de la región, con el significado literal de 'cuatroseando'. Para él, //tahua-sh// es un derivado adjetival constituido por la raíz numeral // tahua-// y el sufijo // -sh//, de significado atributivo, y que es muy productivo no solo en el quechua central (Áncash, Tarma, Junín) sino también en el cajamarquino, y muy posiblemente en la variedad hablada en Santiago de Chuco, hoy extinguida. Dicho sufijo derivativo, al unirse al lexema //tahua-//, le confiere un significado adjetival: 'cuatroso' o 'propenso a ser cuatro'. Es esta forma la que habría sido castellanizada en el habla local, tomando la forma de gerundio con el gramema castellano // ndo// , para expresar el significado 'cuatroseando', es 
decir, «describiendo la posición «doblada en cuatro» que adoptan los ancianos en su extrema vejez». Ubicado en el ámbito literario, Rodolfo piensa que Vallejo podría haber imaginado a los alcanfores encorvándose por la vejez, con la fronda colgada, como se encorvan algunas personas en la senectud, con el tórax inclinado hacia adelante y las extremidades superiores muy distendidas ${ }^{19}$. No dudamos de que, desde la perspectiva del castellano andino, esta es una explicación plausible, sin ningún recurso anagramático. La mejor que hemos podido conocer hasta ahora y que dista mucho de las expuestas por Ángeles y Guzmán.

Si bien la presencia del antiguo sufijo // $-\int / /$ en el quechua de Cajamarca y quizá en el de la sierra liberteña, posibilita una explicación como la precedente. No obstante, la alta frecuencia de uso del fonema $/ \mathrm{f} /$ en el sustrato culle de Santiago de Chuco, en el que no aparece el vocablo \#tahuash $\#^{20}$, induce a ensayar otra elucidación, en la cual nos aventuramos en las líneas siguientes.

\section{Tahuashando: un neologismo poético}

Sin más información que la disponible por entonces, terminamos nuestro trabajo anterior (Rojas 2012) proponiendo dos conjeturas. Una gramatical y otra

19 La explicación resumida en este párrafo ha sido leída por Rodolfo y se publica con su autorización.

20 En el área nuclear culle, no hemos encontrado ningún uso de la palabra \#tahuash\#, solo \#huasha\# ('espalda', 'espinazo') y \#tahuasha\# ('encorvado'), como veremos más adelante. 
semántica. Decíamos que la palabra \#tahuashando\# no se originaba en la voz quechua \#tawa\# (o tahua) y que el fonema $/ \int /$, siendo tan característico de la lengua culle, formaría parte de un posible lexema de dicha lengua. Y ese lexema sería \#taguash\#. No adherimos a este el fonema /-a-/, anterior al gramema //-ndo //, por cuanto corresponde a la vocal temática de los verbos castellanos de primera conjugación.

Referente a la contraparte semántica, estimando los aspectos contextuales del poema y, en especial, el clima tan soledoso y frío, generado poéticamente por Vallejo en torno a la tumba de su madre, pensábamos que el significado estaría vinculado a comportamientos insinuados por los «ponchos de hielo» o por la actitud respetuosa de mostrarse «sin sombrero». A partir de estas suposiciones, decíamos que / tahuashando / significaría algo equivalente, semejante o afín a 'tiritando' o 'temblando', que guardaría relación "con ponchos de hielo», o a gerundios como 'rezando' u 'orando', en correspondencia con la actitud de reverenciar «sin sombrero».

Después de cuatro años de indagaciones, dentro y fuera del área culle, hace pocas semanas, en una conversación con Samuel Blas, uno de mis alumnos de lingüística de la Universidad Nacional de Trujillo, a quien había pedido su colaboración para identificar palabras semejantes al hipotético lexema \#taguash\#, me dijo algo parecido a esto:

-Como soy de Santiago de Chuco, viajo con cierta frecuencia a mi tierra, y nunca hasta ahora he oído una palabra como \#taguash\#. Pero sí he escuchado a personas 
mayores y jóvenes del caserío El Alto ${ }^{21}$, enunciar con cierta frecuencia, por ejemplo:

1. a. Yastá taguasha mi abuelo

b. Taguashón ta el Shesha ${ }^{22}$

c. Hola, huashita

En el acto, intuí que esas eran las palabras que estaba buscando y le pregunté enseguida

- ¿Y qué significan?

-La palabra \#taguasha\# significa 'encorvado' y \#tahuashón\# quiere decir 'muy encorvado' (o tal vez 'encorvadazo'). También usan la palabra \#huashita\# como un apodo afectivo -me respondió.

Luego, recalcó que estos términos se relacionan con el sentido de corvadura de la espalda, pero no de joroba ni de jorobado. Y agregó:

-En las chacras, los campesinos dicen, por ejemplo: «Por aitá tahuashón» (< por ahí está tahuashón), para referirse a un cosechador que, por alguna parte del campo, 'está muy encorvado'.

Esto parecía confirmar mi intuición. En esas palabras estaba aparentemente mi hipotético lexema \#taguash(a)\#, signo del significado ${ }^{23}$ 'encorvado' que, seguido del apreciativo castellano // -on //, se utiliza para denotar a una persona 'muy encorvada'. Sin embargo, debí

21 El Alto es un caserío del distrito de Mollepata, ubicado en la provincia de Santiago de Chuco.

22 Hipocorístico culle del nombre propio César.

23 Por cierto, no compartimos la idea saussuriana de que el signo lingüístico es una realidad biplana conformada por un significante y un significado. Puesto que tales elementos son de naturaleza muy diferente. El significante es una realidad sonora (física) y el significado es una realidad abstracta (mental), por consiguiente, no pueden integrarse en una unidad (Rojas 2014a). 
replantear de inmediato esta apreciación, porque al contrastar las formas \#huashita\#, \#tahuasha\#, y \#tahuashón\#, se observa en la primera el segmento //-it- //, es decir, el infijo castellano apreciativo, que no aparece en las dos restantes. Si elidimos tal infijo, podríamos suponer que // huasha // es un lexema culle. Asimismo, hay un elemento morfofonológico que aparece en la segunda y tercera, pero no en la primera. Desde luego, dicho elemento no puede ser sino la forma verbal \#está\#, reducida a \#-ta\# por una aféresis. Recordé de inmediato algunos enunciados producidos usualmente por personas procedentes de la sierra de La Libertad, pronunciados con un alargamiento del vocal de la penúltima sílaba y una entonación afectuosa muy particular, como:

2. a. «Taste» buenita < «Está usted» buenita.

b. «Taste» buenmozo < «Está usted» buenmozo.

c. «Taste» apurao < «Está usted» apurado.

Expresiones en las que, obviamente, una aféresis reduce la forma verbal \# es.tá\# a \#-ta\# ${ }^{24}$, sin ningún cambio de significado: verbo 'estar', en el presente del modo indicativo, tercera persona singular. La misma forma que significa segunda persona, singular del presente indicativo, cuando se relaciona con el pronombre de segunda persona singular: \# usted\#.

Un proceso igual determina la pérdida del primer fonema: / u- / del pronombre \# us.ted\# y un apócope, la supresión del fonema final: /-d/ de la misma palabra. En consecuencia, queda reducida a \#-s.té-\#. Y como

24 La aféresis de la forma verbal / es.tá/ > /-tá/ es un fenómeno generalizado en el habla popular. 
en castellano el fonema / / no tiene el rasgo silábico (no puede funcionar como núcleo de sílaba y tampoco conformar sílaba por sí sola), ni es posible su aparición en la secuencia fonemática /st-/ en posición inicial de palabra, \#-s.té-\# se liga, necesariamente, a la vocal precedente /-a/ de la forma verbal \#-ta\#. Este proceso fonológico origina una nueva palabra compuesta: \# taste\# en el dialecto andino de la sierra liberteña, con una resilabificación diferente: \#tas.te\#. Aun así, ambas palabras conservan su significado. Esto se evidencia cuando un poblador de esta región entiende perfectamente oraciones como: «está usted bien de salud», «está usted enfermita, cuídese» o «está usted muy alegre», pronunciadas por personas de otra área dialectal.

En el habla descuidada (en especial, en los sectores populares), dicha forma verbal reducida a \# ta\#, es muy frecuente en expresiones como: «ta bien», «ta rico», «ta buenaza», «ta trabajando», «ta que juega», «ta jato», etc. Siendo así, en \#tahuasha\# y en \#tahuashón\#, es posible aislar el lexema verbal: // ta- //. Hecha esta operación y, considerando que la parte final de \#tahuashón\# corresponde al sufijo castellano // -ón ///, podríamos insistir en la conjetura de que //huash(a) // es un nombre de origen culle; asimismo, inferir que la palabra \#tahuashón\# está constituida por tres elementos morfofonológicos: un verbo: \#ta\#, un nombre: //-huash(a)-// y un sufijo: // -on // (sufijo apreciativo, que sustituye al vocal final del nombre). Identificados el primero y el tercero como unidades castellanas, lo único que falta es averiguar la filiación del segmento //-huasha-// (o //-huash-//). Tarea sobre la cual nos referimos a continuación. 
A primera vista, por la presencia del fonema $/ \int /$, representado por el dígrafo -sh-, nos inclinamos a pensar que \#huasha\# podría ser una voz culle pero, por el añoso y extenso uso de la lengua de los incas en la sierra liberteña, así como por las abundantes interferencias producidas entre ambas lenguas en contacto, también es posible que pudiese ser una voz quechua cullificada. Desde esta perspectiva, teniendo en consideración que en quechua no existe el indicado fonema, debimos buscar en los lexicones más antiguos de esta lengua algo semejante a \#wach\# o \#wacha\# (huach/ huacha); a \#was\# o \#wasa\# (huas/huasa). En nuestra búsqueda lexicográfica encontramos la siguiente información.

3. En el Lexicón de la lengua quichua de fray Domingo de Santo Thomas (1560):

Guassa $^{25}{ }_{\text {_ }}$ espaldas de cualquier animal.

Guassa tullun_-_ cerro de las espaldas.

Cerro entre las espaldas_ _ - guassa tulluc.

Espalda_ _ guassa.

4. En el Vocabulario (1951 [1586]), considerado anónimo: Huassa, espalda.

Huassa rimac, murmurador [que habla de alguien a espaldas de este].

Huassa tullu ${ }^{26}$, espinazo

Espinazo, huassa tullu, huassap challhuan.

25 Fray Domingo, en su Lexicón, registra la palabra quechua \#wassa\# en esta forma: «Guassa», porque hasta 1560 (año de publicación del Lexicón), la jerarquía eclesiástica del virreinato peruano no había establecido ninguna norma acerca de la escritura de la lengua andina. Solo después del Tercer Concilio Limense (1583) señala que las palabras quechuas que comiencen con la secuencia vocálica / ua- / o / ue-/ deben ser escritas con una «h» precedente: «hua-», «hue-», tal como se hacía en castellano.

26 En el Vocabulario anónimo (1586), tullu significa «hueso». Por consiguiente, «huassa tullu» significaría «hueso de la espalda». 
5. En el Vocabulario de la lengua Qquichua de Diego González Holguín (2007):

Huassa huacta $^{27}$. [Costillas] De las espaldas.

Huassuman. A las espaldas.

Huassaypi. A cuestas o en mis espaldas.

Quimray. Lo ancho, las provincias o lugar y el districto cuzco quimray, o hacia o cerca del Cuzco.

Quimrayçapa. Demasiado de ancho o anchi corto.

Espaldas. Huassa.

Espaldudo. [Huassa] Quimrayçapa o huassa çapa [espaldas demasiado anchas o espaldas anchas].

Por lo visto, «guassa» o «huassa» son registros correspondientes a la palabra quechua \#wassa\# que significa 'espalda' o 'espaldas', realizados en diferentes momentos. El primer registro es de 1560, antes de la normalización de la escritura quechua compatibilizada con la castellana. El segundo, de 1586, y el tercero, de 1607, fueron efectuados después de la mencionada normalización establecida por la Iglesia católica en el Tercer Concilio Limense (1583). Tanto en el Vocabulario de 1586 (considerado anónimo), cuyo autor sería el jesuita peruano Blas Valera (Rojas 2016), como en el de Diego González de 1607, en ningún lema se hace referencia a una joroba; solo a «espaldas» que pueden ser anchas o demasiado anchas. En cambio, el dominico Santo Thomas sí anota «Guassa tullun» con el significado 'cerro de las espaldas' en alusión a una malformación de la columna vertebral y de las costillas, que produce un abultamiento de forma convexa en las espaldas, esto es, una joroba o corcova. Sin embargo, en el Vocabulario de 1586, «Huassa tullu» significa

27 Esta palabra quechua, en el Vocabulario de González Holguín, significa 'costillas'. 
específicamente 'espinazo' o columna vertebral. La diferencia semántica podría ser dialectal, de acuerdo con el quechua que habría practicado cada uno de los autores.

En la actualidad, en la antigua área culle, el lexema // huasha // (o//-huash- //) es de uso muy extendido. También el vocablo culle \#cailengo\# ${ }^{28}$ o \#cailingo\#, con el cual se designa en forma figurada a un 'jorobado' o 'corcovado', aunque para este significado se usa con más frecuencia la palabra \#curcunsho\# (<curcuncho, cast.). En el área culle, no hemos podido registrar ninguna otra referida a la espalda. Parecería que, en la actualidad, el uso de las voces \#tahuasha\# y \# tahuashón\# estuviera circunscrito al área de Santiago de Chuco, especialmente a Mollepata y Mollepampa, según una información de Percy Barriga, otro estudiante de lingüística de la UNT.

En cierta ocasión, conversando sobre estos temas con Emilio León, profesor en un caserío cercano a Huamachuco, me contó que muchas personas adultas de la provincia de Sánchez Carrión suelen decir: «Me duele la guasha» para significar 'me duele el espinazo'. Testimonio con el cual coincidió el poeta Santiago Aguilar en un diálogo amistoso con aroma de café. En Santiago de Chuco también se escucha expresiones como esta: «Ta que me duele la huasha». Evidentemente, en estos enunciados, \#huasha\# significa 'columna vertebral' a la altura de la espalda,

28 Sustantivo con el que se designa al escarabajo, coleóptero coprófago de dorso abultado, por eso, por analogía se utiliza para hacer referencia a personas sucias $\mathrm{y}$, en otros casos, a personas jorobadas, con intención peyorativa. 
sin ninguna alusión a 'encorvadura'. Aquí se nota con toda claridad una marcada diferencia semántica entre \#tahuasha\# ('encorbado') y \#guasha\# ('espalda' o 'espinazo').

Teniendo en cuenta este hecho y la información lexicográfica examinada, se puede inferir, de acuerdo con la suposición planteada, que el lexema //-huasha- // del gerundio \#tahuashando\# proviene del vocablo quechua / wassa/con el que se expresa el significado 'espalda' o 'espaldas', cullificado mediante interferencias fonológicas. En primer lugar, el deslizante quechua /w-/ (o semiconsonante, según otra terminología), ubicado en posición inicial de palabra, es sustituido por el fonema culle /g-/. Y, en segundo lugar, el rasgo alveolar del fonema quechua /s / es desplazado por el rasgo posalveolar del fonema culle $/ \int /$. Cambios que, en el prolongado contacto, habrían producido la voz /guasha/ (escrita como «huasha», según las convenciones de la escritura castellana). Desde este punto de vista, es obvio que el significado del gerundio \#tahuashando\# debe estar vinculado a la espalda, a la forma de esta, y no a otra realidad. Menos aún, a entidades cuantificables.

Lo examinado hasta aquí nos permite ver el neologismo \#tahuashando\#, creado por Vallejo ${ }^{29}$, como el resultado de un proceso de composición y de flexión, de acuerdo con las normas combinatorias de la lengua castellana. Al respecto, recordemos que en nuestra lengua

29 Afirmamos esto porque ninguna de las personas ancianas consultadas en la sierra liberteña, en especial en Santiago de Chuco y en los distritos de Mollepata y Mollepampa, conoce esta palabra y menos su significado. 
y en muchas otras, uno de los procesos morfológicos para la formación de palabras consiste en la unión de un verbo con un nombre $(\mathrm{V}+\mathrm{N})$ para generar nombres compuestos. Por ejemplo: sacacorchos, cortaúñas, pararrayos, espantapájaros, que conservan los significados de los lexemas básicos. Pero no sucede lo mismo con compuestos nominales como \#rascacielos\# (calco del inglés skyscraper que, literalmente significa 'rascador del cielo') y \#saltaperico\#, cuyos significados básicos son sustituidos por otro:

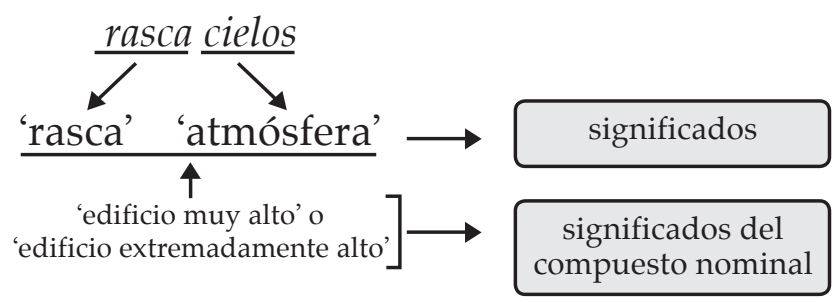

Como se ve, el compuesto nominal rascacielos adquiere un significado completamente diferente a los de los lexemas que lo constituyen. Lo mismo se puede observar en saltaperico:

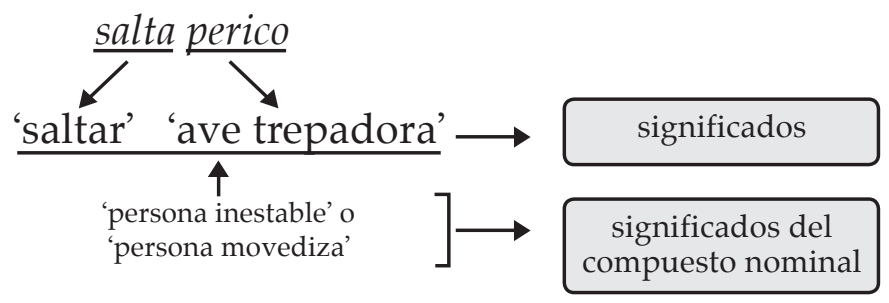

Al entrar en contacto el castellano con el culle, en el antiguo territorio de los huamachucos, un proceso 
parecido habría producido la palabra compuesta adjetival \#tahuasha\# (verbo+nombre) para expresar un significado como 'encorvado', esto es, con la espalda 'curvada', 'flexionada', 'doblada', 'inclinada', 'arqueada' o 'agobiada', pero no jorobada.

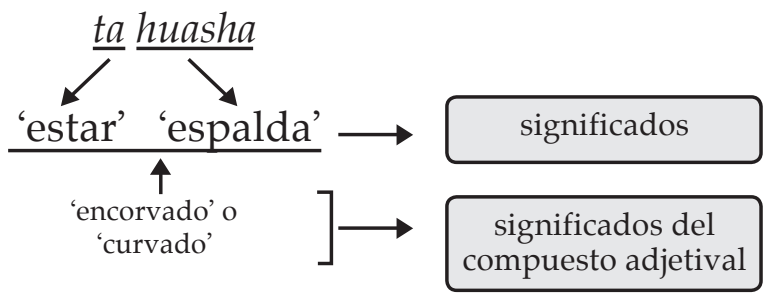

Por cierto, este procedimiento morfológico no es productivo en la lengua castellana. En esta, regularmente, los compuestos adjetivales se forman por la unión de dos adjetivos: rojiblanco, de un nombre y un adjetivo: pelirrojo, de un adverbio y un adjetivo: malhablado. Pero aquí, en el castellano andino liberteño, tenemos un adjetivo compuesto por un verbo copulativo castellano y un nombre culle de origen quechua: \#tahuasha\# (/\#tahuash\#, tan parecido al lexema que imaginábamos antes).

Siendo así, es razonable pensar que el joven poeta hubiese tomado este compuesto adjetival del dialecto de su tierra natal y lo hubiese convertido en el verbo \#tahuashar\#, al que luego habría flexionado con el gramema //-ndo // para usarlo en la forma de gerundio: \#tahuashando\#, con sentido de imperfectividad, de continuidad, como la expresión de 'encorvando', 'flexionando' o 'curvando', es decir, inclinando el tórax hacia adelante o doblando la espalda por la 
edad (¿de los viejos alcanfores $?^{30}$ ). Significados relacionados con la actitud reverencial atribuida a aquellos árboles vetustos, de quitarse el sombrero ante un hecho solemne o grave. Lo cual hace pensar que Vallejo habría usado el gerundio "tahuashando», pero no para expresar el significado común 'encorvando', sino, metafóricamente, 'reverenciando', que concuerda a cabalidad con el habitual gesto cortés de los huamachucos ${ }^{31}$ de antes y de ahora, asimismo con el sentido de los versos finales de «Hojas de ébano». Y aun cuando el poeta podría haber escrito:

$$
\begin{aligned}
& \text {... los viejos alcanfores } \\
& \text { que velan [reverenciando] en el sendero } \\
& \text { con sus ponchos de hielo }{ }^{32} \text { y sin sombrero. }
\end{aligned}
$$

Prefirió -como decíamos (Rojas 2012)- la eufonía poética de «tahuashando» y el sentimiento creado por la palabra: de cercanía afectiva con su madre -una de las «Marías que se van»-. Nosotros seguiremos tahuashando la poesía eterna de este peruano universal.

30 En sus primeros años de desarrollo, los alcanfores se mecen con la fuerza del viento porque son muy flexibles, tanto que, según cuenta Samuel Blas, solía columpiarse de sus ramas cuando era niño. Pero después de algunos años se van haciendo maderables y sus ramas adquieren ligeramente la forma de un poncho airoso y, a la vera de los caminos, envejecen y se encorvan como reverenciando a los caminantes.

31 Todavía hoy un buen sector de la población de la sierra liberteña conserva la costumbre de quitarse el sombrero e inclinar ligeramente el cuerpo hacia adelante, como una reverencia ante una persona a la que se saluda con respeto muy especial.

32 La fronda de los alcanfores blancos, cuando estos envejecen, adquiere una coloración blanquecina como la de la nieve congelada. 


\section{Bibliografía}

ANÓNIMO. Vocabulario y phrasis en la lengua general de los indios del Perú llamada quichua, y en la lengua española. Lima, Instituto de Historia de la Facultad de Letras de la UNMSM, 1951 [1586].

ADELAAR, Willem F. H. «En pos de la lengua culle», en Rodolfo Cerrón y Gustavo Solís (eds.). Temas de lingüística amerindia. Lima, CONCYTEC y GTZ, 1989, págs. 83-105.

ÁNGELES CABALLERO, César Augusto. «Peruanismos en la literatura peruana: César Vallejo», en La Crónica Dominical. Lima, 19 de junio de 1955, pág. 6.

AGUSTINOS. Relación de la religión y ritos del Perú hecha por los padres agustinos. Edición, estudio preliminar y notas de Lucila Castro Gubbins. Lima, Pontificia Universidad Católica del Perú, 1992 [c1561] $]^{33}$.

BOSQUE, Ignacio y Violenta DEMONTE (dir.). Gramática descriptiva de la lengua española. 3 vols. Madrid, Editorial Espasa Calpe, 1999.

EDICIONES SM. Clave. Diccionario de uso del español actual. Madrid, Ediciones SM, 2000.

ESTETE, Miguel de. Noticia del Perú, en Varios autores. El Perú a través de los siglos. Biblioteca Peruana. T. I. Lima, Editores Técnicos Asociados, 1968, págs. 345-402.

. «Relación del viaje que hizo el señor Capitán Hernando Pizarro por mandato del señor Gobernador, su hermano, desde el pueblo de Caxamalca a Parcama, y de allí a

33 La letra «c» que aparece delante de una fecha incierta, como en este caso, significa 'cerca de'. 
Jauja». En Jerez. El Perú a través de los siglos. Biblioteca Peruana. T. I. Lima, Editores Técnicos Asociados, 1534, págs. 242-257.

FÁBREGAS, Antonio. Morfología. El análisis de la palabra compleja. Madrid, Editorial Síntesis, 2013.

GONZÁLEZ HOLGUÍN, Diego, S. J. Vocabulario de la lengua general de todo el Perú llamada lengua Qquichua o del Inca. Prólogo de Raúl Porras Barrenechea. Lima, Instituto de Historia de la Facultad de Letras de la UNMSM, 1952 [1607].

GUITART, Jorge. Sonido y sentido: teoría y práctica de la pronunciación del español. Georgetown, Georgetown University Press, 2004.

GUZMÁN, Jorge. Tahuashando. Lectura mestiza de César Vallejo. 2. ${ }^{a}$ ed. Santiago de Chile, LOM Ediciones, 2000 [1991].

HUALDE, José Ignacio. Los sonidos del español. New York, Cambridge University Press, 2014.

JAKOBSON, Roman. «Lingüística y poética». En Ensayos de lingüística general. Barcelona, Editorial Seix Barral, 1975, págs. 347-395.

. Ensayos de lingüística general. Barcelona, Editorial Seix Barral, 1975.

LARREA, Juan (ed.). César Vallejo. Poesía completa. Introducción, notas y vocabulario de las obras poéticas de Vallejo. Barcelona, Barral Editores, 1978.

MARTICORENA QUINTANILLA, Manuel. El sustrato quechua en "Los heraldos negros». Serie: Cuadernos de Nueva Cultura. Iquitos, Asociación Nueva Cultura, 1993. 
MOLINER, María. Diccionario de uso del español. Madrid, Editorial Gredos, 1970.

MONGUIÓ, Luis. César Vallejo. Vida y obra. Lima, Editora Perú Nuevo, 1952.

MORENO C., Carlos. Curso universitario de lingüística general. Semántica, pragmática, morfología y fonología. T. 2. 2. ${ }^{a}$ ed. Madrid, Editorial Síntesis, 2000.

PIZARRO, Pedro. Relación del descubrimiento y conquista de los reinos del Perú. Varios autores. 1968 [1571], págs. 439-586.

REAL ACADEMIA ESPAÑOLA Y ASOCIACIÓN DE ACADEMIAS DE LA LENGUA ESPAÑOLA. Nueva gramática de la lengua española. 3 vols. Madrid, Espasa Libros, 2009.

ROJAS, Íbico. «Blas Valera. El primer lingüista peruano». En proceso de edición, 2016.

- «Voces culles en la poesía de César Vallejo», en Pueblo Continente. Vol. 23. $\mathrm{N}^{\circ}$ 2. Trujillo, Universidad Particular Antenor Orrego, 2012, págs. 483-491. También en Espergesia. Revista Literaria y de Investigación. Año 10. Vol. 1 y 2, enero-diciembre. Trujillo, Universidad César Vallejo, 2014, págs. 34-51.

. Origen y expansión del quechua. Lima, Editorial San Marcos, 2014a.

. Saussure. Signo y principios lingüísticos. Lima, Editorial San Marcos, 2014b.

. «Culle: las voces del silencio», en Luis G. Lumbreras y otros. Los Huamachucos: Testimonios de una gran cultura. Lima, Asociación Civil Ruta Moche, 2013, págs. 174-217. 
SANTO THOMAS, Domingo de, O. P. Lexicón o vocabulario de la lengua general del Perv. Edición facsimilar, con prólogo de Raúl Porras Barrenechea. Lima, Instituto de Historia de la Facultad de Letras de la UNMSM, 1951 [1560].

STEINER, George. Extraterritorial. Ensayos sobre literatura y la revolución del lenguaje. Buenos Aires, Adriana Hidalgo Editora, 1971.

. Gramáticas de la creación. Madrid, Ediciones Siruela, 2011 [1999].

VALERA, Soledad. Morfología léxica: La formación de palabras. Madrid, Editorial Gredos, 2005.

VALLEJO, César. César Vallejo. Poesía completa. Edición crítica y exegética de Juan Larrea. Barcelona, Barral Editores, 1978.

. César Vallejo. Poemas completos. Edición crítica de Ricardo González Vigil. Lima, Petróleos del Perú, Ediciones Copé, 2012. 